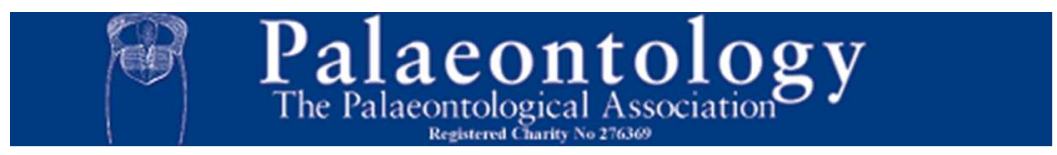

\title{
Modelling enrolment in Cambrian trilobites
}

\begin{tabular}{|r|l|}
\hline Journal: & Palaeontology \\
\hline Manuscript ID & PALA-11-16-3901-OA.R1 \\
\hline Danuscript Type: & Original Article \\
\hline Complete List of Authors: & $\begin{array}{l}\text { Esteve, Jorge; Universidad Complutense de Madrid, Paleontologia } \\
\text { Rubio, Pedro; Burashi S.L } \\
\text { Zamora, Samuel; Área y Museo de Paleontología, Universidad de Zaragoza, } \\
\text { Departamento de Ciencias de la Tierra; Instituto Geologico y Minero de } \\
\text { Espana } \\
\text { Rahman, Imran; University of Bristol, School of Earth Sciences; University } \\
\text { of Oxford, Museum of Natural History }\end{array}$ \\
\hline Key words: & $\begin{array}{l}\text { Conocoryphidae, Palaeozoic, X-ray microtomography, functional } \\
\text { morphology, biomechanics }\end{array}$ \\
\hline &
\end{tabular}

\section{SCHOLARONE ${ }^{\text {m }}$}

Manuscripts 


\author{
Modelling enrolment in Cambrian trilobites \\ by JORGE ESTEVE ${ }^{1}$, PEDRO RUBIO ${ }^{2}$, SAMUEL ZAMORA ${ }^{3}$ and IMRAN A. RAHMAN ${ }^{4}$ \\ ${ }^{1}$ Departamento de Paleontología (UCM), c/ José Antonio Novais 12, 28040 Madrid, Spain, \\ ${ }^{2}$ Burashi S.L., Avda. Ma Zambrano 24, 50018 Zaragoza, Spain \\ ${ }^{3}$ Instituto Geológico y Minero de España, c/ Manuel Lasala 44, 10 9³, 50006 Zaragoza, Spain \\ ${ }^{4}$ Oxford University Museum of Natural History, Parks Road, Oxford, OX1 3PW, United \\ Kingdom \\ * Corresponding author
}

\begin{abstract}
Trilobites were capable of enrolling in different ways based on the flexible articulation of thoracic segments and associated interlocking devices; the type of enrolment (spiral or sphaeroidal) is thought to have largely depended on the coaptative devices that each trilobite used to enclose the body. Based on X-ray microtomography scans of complete enrolled specimens from the Cambrian, we created three-dimensional (3-D) computer models to assess the kinematics needed to achieve both enrolment types. We demonstrate that closely related trilobites with little morphological variation (Bailiaspis?, Conocoryphe and Parabailiella) developed different enrolment types as a result of small variations in the number of thoracic segments and the angle between adjacent segments. Moreover, our models indicate that sphaeroidal enrolment, which is associated with a smaller number of thoracic segments, enabled faster encapsulation. This supports the hypothesis that there was a trend in the evolution of trilobites towards reduction in the number of thoracic segments in phylogenetically derived taxa in order to enhance the efficiency of enrolment.
\end{abstract}

Key words: Conocoryphidae, Palaeozoic, X-ray microtomography, functional morphology, biomechanics 
Enrolment was an adaptive behaviour in trilobites that provided effective defence against predators and/or adverse environmental conditions (Esteve et al. 2011). It is documented for some of the earliest trilobites from the Cambrian (Ortega-Hernandez et al. 2013) and the ability persisted throughout the Palaeozoic until the Permian (Lerosey-Aubril \& Angiolini 2009). The fossil record of trilobites archives functionally significant enrolment variation, demonstrably associated with coaptative devices and body pattern differences (Begström 1973; Esteve 2013). This variation is chiefly related to the relative position of the pygidium with respect to the cephalon. If the pygidium is hidden beneath the cephalon, the enrolment is called "spiral-type", whereas if the pygidium rests below the cephalon (margin to margin), the enrolment is called "sphaeroidal-type" (after Begström 1973). Substantial variation in enrolment has been observed within the same trilobite lineages (Henry and Clarkson 1974; Esteve et al. 2010), but the morphological differences required to achieve a specific type of enrolment in phylogenetically close trilobite clades are poorly understood.

Here, we describe three enrolled Cambrian trilobites, which belong to the same clade and exhibit two different enrolment-types. The trilobites are members of the family Conocoryphidae Angelin, 1854, which is one of the four recognized families of blind Cambrian ptychopariid trilobites and is known from Gondwana and Baltica (Cotton 2001). Several authors have described enrolment in this family over the past 60 years (e.g. Šnajdr 1958; Bergström 1973; Esteve 2009). However, the biomechanics and evolution of enrolment are poorly understood, not only in this particular family, but also in all trilobites. Contrary to other enrolled trilobites known from the Cambrian, the fossils are three-dimensionally preserved, enabling the extraction of detailed morphological information. This allowed us to create accurate 3-D reconstructions of Bailiaspis? glabrata and Parabailella languedocensis based on nondestructive X-ray microtomography scans. These form the basis of computer models of enrolment, which shed light on the functional morphology and kinematics of this behaviour, with implications for the evolutionary history of different enrolment types. 


\section{MATERIAL AND METHODS}

Fossils

Three genera belonging to the trilobite family Conocoryphidae were examined for this study: (i) Bailiaspis? (Fig. 1), (ii) Parabailella (Figs 2, 3D-E) and (iii) Conocoryphe (Fig. 3A-C). (i) Bailiaspis? was represented by four enrolled specimens of Bailiaspis? glabrata (Angelin, 1854) (MPZ 2012/57, MPZ2017/310-312), which are three-dimensionally preserved as external moulds in siliceous concretions and came originally from rocks belonging to the Valtorres Formation (Cambrian Series 3, Guzhangian Stage) at Purujosa, northeast Spain (see Álvaro et al. 2013 for details of the locality). (ii) Parabailella was represented by an internal mould of an enrolled specimen of Parabailella languedocensis Thoral, 1946 (C-12), which is threedimensionally preserved and came from lowermost part of the Jince Formation (Cambrian Series 3, Drumian Stage) at the hill slope of Vinice near Jince in the Barrandian area, Czech Republic (see Fatka and Szabad 2014 for details of the locality), as well as five external moulds of the same species (MPZ2017/314-318), also enrolled or semi-enrolled and three-dimensional preserved, which are from the lowermost part of the Murero Formation (Cambrian Series 3, Drumian Stage) at Purujosa (see Zamora et al. 2013 for details of the locality). Conocoryphe was represented by seven new enrolled specimens of Conocoryphe heberti (Munier-Chalmas \& Bergeron in Bergeron, 1889) (MPZ2017/319-325), preserved as internal and external moulds, which were collected from the Purujosa trilobite assemblage at the top of the Murero Formation (Cambrian Series 3, Drumian Stage) at Purujosa, northeast Spain (see Zamora 2010; Esteve et al. 2011 for details of the locality).

The varying modes of preservation of these conocoryphid trilobites allowed their enrolment to be studied in detail using different methods. The external moulds were studied using latex casts (Figs 1D-H, 3A-E). The internal moulds and latex casts were coated with ammonium chloride and photographed with a digital camera (Figs 2, 3F-I). Additionally, two adjacent specimens of Bailiaspis? glabrata preserved as external moulds in the same concretion and the internal mould of Parabailella languedocensis were imaged using non-destructive Xray microtomography (XMT) (see below). 
All the specimens are housed in Museo de Ciencias Naturales of the Zaragoza University (MPZ), except the single specimen of Parabailella languedocensis from the Czech Republic, which is housed at the Horák Museum in Rokycany (C-12).

\section{X-ray microtomography}

Two specimens from Spain (MPZ2016/1 and MPZ2016/2) and one from the Czech Republic (C-12) were visualized as 3-D digital reconstructions using a combination of XMT and the freely-available SPIERS software suite (Sutton et al. 2012). Specimens were imaged with a Nikon Metrology HMX ST 225 scanner at the Natural History Museum, London. MPZ2016/1 and MPZ2016/2 were scanned together using a voltage of $210 \mathrm{kV}$, a current of $190 \mu \mathrm{A}$, a 0.5 $\mathrm{mm}$ thick copper filter and 3142 projections (each with an exposure time of $708 \mathrm{~ms}$ ). C-12 was scanned using a voltage of $200 \mathrm{kV}$, a current of $181 \mu \mathrm{A}$, a $0.1 \mathrm{~mm}$ thick copper filter and 3142 projections (each with an exposure time of $708 \mathrm{~ms}$ ). Slices were reconstructed in Nikon CT Pro software using filtered back projection, giving tomographic datasets with voxel sizes of $24 \mu \mathrm{m}$ (MPZ2016/1 and MPZ2016/2) and $15 \mu \mathrm{m}(\mathrm{C}-12)$.

The scan of MPZ2016/1 and MPZ2016/2 was digitally reconstructed by applying an inverted linear threshold to the dataset and manually assigning each of the specimens to a separate region-of-interest. In addition, the cephalon, thorax and pygidium of were MPZ2016/1 assigned to distinct regions-of-interest. For C-12, a linear threshold was applied to the dataset and the cephalon, thorax and pygidium were assigned to different regions-of-interest. Isosurfaces were then rendered to give interactive three-dimensional reconstructions of the specimens, which were subjected to weak smoothing and island removal to minimize noise. XMT slices and the resulting 3-D reconstructions are provided as supplementary information.

\section{Computer models of enrolment}

The 3-D reconstruction of the best-preserved specimen of Bailiaspis? glabrata (MPZ2016/1) was imported into the open-source 3-D graphics and animation software Blender (https://www.blender.org/). This was done so that the different morphological elements could be 
digitally distinguished and their relative movements deduced, informing the computer models of enrolment. First, each of the tergites was retopologized through polygonal subdivision; this resulted in a much lower-resolution model that still accurately described the geometry of the original specimen. The cephalon and pygidium were relatively well preserved, but the preservation of the thorax varied from segment to segment; poorly preserved segments were digitally rebuilt (by careful reference to better preserved segments, as well as observations of other specimens, e.g. Fig. 3J-K) to generate an accurate model of the entire fossil. Using this model, we created a rig that allowed us to describe the kinematics of each tergite. To define the kinematics mode, we first had to establish the centre and axis of rotation for each tergite. Based on Bruton and Haas (1997), we assigned these to the anterior edge of the pleura that fits below the posterior edge of the previous segment (Fig. 4A-C). The variation around the axis of rotation for successive segments can be described with a logarithmic expression (Fig. 5A-B). In our study, we began with an enrolled specimen, and from this, we were able to find the parameters of the logarithmic expression that were compatible with the geometry of the unrolled (i.e. prone) copy. This was done graphically for the values of these variables and the results were displayed in real-time in the trilobite model (see Supplementary Movie 1). Once we had obtained a prone model, we were able to experiment with alternative enrolment types, applying variations of the previous expression and visualizing its results graphically. In addition, we modified the number of segments in the thorax, obtaining separate models of enrolment for a trilobite with 14 and 15 thoracic segments. This allowed us to investigate how small differences in morphology could result in different enrolment types (i.e. sphaeroidal vs spiral), as well as the different parameters needed for each type of enrolment.

\section{RESULTS}

\section{Morphological description}

- Bailiaspis? glabrata: The trunk consists of 15 free segments in the thorax and three fused segments in the pygidium. The specimens are generally well preserved and have not been strongly affected by taphonomic distortion. The flexion between the first segment and the 
cephalon is $\sim 44.6^{\circ}$. The enrolled specimens show that most of the flexure in the trunk is accommodated within the anterior part of the thorax (first five segments), with minimal flexion in the posterior segments (Fig. 1B, F). Bailiaspis? glabrata shows the typical spiral configuration, where the pygidium is resting with its dorsal side on the cephalic marginal doublure and the pleural tips fit within the furrow below the doublure (Fig. 1B-C, G).

- Parabailella languedocensis: 14 free segments make up the thorax and three fused segments the pygidium. The single specimen from the Czech Republic is slightly distorted, but the original volume of the specimen was unaffected. The enrolled specimens show that the flexion between the cephalon and the first segment is $\sim 46.2^{\circ}$ (Fig. 2). As with B.? glabrata, maximum flexion occurs chiefly within the anterior part of the thorax (first six segments), while there is limited flexion among the posterior segments. The cephalon shows an anterior gentle arch where the pygidium is resting with its ventral side on the cephalic marginal doublure and the pleural tips fit within the furrow below the doublure (Fig. 2). The Spanish specimens only preserve the cephalon and first five thoracic segments, indicating that most of the flexure is also accommodated in the anterior part of the thorax (Fig. 3D-E). The Czech specimen clearly shows the pygidium situated beneath the cephalon, indicating a sphaeroidal enrolment-type (Fig. 2).

- Conocoryphe heberti: 14 free segments (thorax) and three fused segments (pygidium) in the trunk. The enrolled specimens demonstrate there is a direct contact between the ventral side of the head and the posterior end of the trunk. Most of the trunk segments (third to fourteenth thoracic segments) are symmetrically flexed under the cephalon. The overlapping pattern of the thoracic segments suggests that this configuration is a result of the ventral flexure of the body. The pygidium is always visible in dorsal view in the rear part of the trunk, demonstrating a sphaeroidal enrolment-type. The tips of the posterior pleural segments fit into the dorsal furrow under the doublure, indicating encapsulated enrolment (Fig. 3A-C).

\section{Enrolment kinematics}

The movement to enrol is transmitted by the articulation half ring from the anterior of the trunk to the rear, first by flexing the anterior part of the trunk downwards and then by flexing the 
more posterior trunk segments downwards and forwards. The studied specimens of conocoryphids show that the angle between the cephalon and the first thoracic segment is around $45^{\circ}$ (Figs 1, 2, 3D-F). Thus, in order to assess the angles between adjacent segments during enrolment, this angle was used in the prone copy to model the enrolment procedure. The computer model provides the flexion angle between adjacent segments during enrolment, from the prone copy to the enrolled configuration (Fig. 5A-B). This final configuration agrees with the shape of the original fossil specimen. This suggests that the angle of $45^{\circ}$ between the cephalon and first segment is correct.

After establishing the degree of flexion between the cephalon and the trunk, the three models created were used to assess both spiral and sphaeroidal enrolment types, providing the angles between adjacent segments throughout the trunk. The kinematic model with 15 segments in the thorax achieved an encapsulated spiral enrolment type with a very gently sloping curve with maximum angles between adjacent segments of between 13 and $23^{\circ}$ (Fig. 5B). The greatest flexion is seen in the anterior part of the thorax, with the ratio between the angles of adjacent segments decreasing towards the rear (Fig. 5C). However, the model of a body with 14 segments and a sphaeroidal enrolment-type (encapsulated) produces a more steeply sloping curve (Fig. 5B) with lower maximum angles between adjacent segments of between 3 and $22^{\circ}$. The ratios between angles of adjacent segments are fairly consistent, increasing somewhat towards the rear of the trunk (Fig. 5C). A third model with 15 segments and a sphaeroidal enrolment type provides higher angles between segments in the anterior and lower angles between segments in the posterior compared to the spiral enrolment model (Fig. 5B). In contrast to the other two models, this model is unable to fully encapsulate the trilobite body (Fig. 5B).

\section{DISCUSSION}

Conocoryphids exhibit two different enrolment-types. Conocorphe heberti and P. arabailella langedocensis both have 14 thoracic segments and show sphaeroidal enrolment-type, whereas Bailella? grabata have 15 segments and is enrolled spirally. Our computer models demonstrate that trilobites with the same number of segments (e.g. 15) could achieve different enrolment 
type (i.e. spiral and sphaeroidal). However, encapsulation in the sphaeroidal enrolment type is more tightly closed when one segment is removed. The computer models also demonstrate that the angle to begin the enrolment procedure, between the cephalon and the trunk, should be around $45^{\circ}$, which agrees with what is documented from direct observation of the fossils.

Most of the genera within the family Conocoryphidae, with the exception of Conocorphe and Parabailella, show a spiral enrolment type. Bergström (1973) described Conocoryphe sulzeri with spiral enrolment type (double type according to Bergström, 1973); however, the specimen figured by Šnajdr (1958, pl. 33 fig. 5) shows a sphaeroidal enrolment type. Figure 3 shows two phylogenetic hypotheses for the conocoryphid clade, rooted using either Elrathia kingii (Fig. 5D) or Ptychoparia striata (Fig. 5E) (Cotton 2001). Ptychoparia striata bears 20 trunk segments (14 thoracic segments and 6 pygidial segments) while Elrathia kingii bears 19 trunk segments (13 thoracic segments and 6 pygidial segments), but both enrolled spirally (Šnajdr 1958, pl 38 fig. 17; Esteve et al. 2011). Conversely, other ptychopariids with less than 15 segments in the trunk, such as Solenopleuropsis ribeiroi or Pardailhania hispida, had a sphaeroidal enrolment-type, whereas $S$. thorali and $S$. rouayrouxi (with more than 15 segments in the thorax) tucked their pygidia beneath the ventral surface of the cephalon achieving a spiral enrolment-type (Esteve et al. 2010). This suggests that a higher number of segments in the trunk favoured the spiral enrolment-type in ptychopariids.

Hughes et al. (1999) reported a trend towards reduction of segments in the thorax and the increment in the number of segments in the pygidium through time. These authors suggested that this trend (called caudalization) is a direct consequence of improvements to enrolment brought about by the presence of larger pygidia that more efficiently covered the ventral side of the body. This shift towards decreasing the number of thoracic segments within clades has not yet been quantitatively tested. However, according to the results of our models, the sphaeroidal enrolment-type model is more efficient compared to the spiral model, with lower angles between adjacent segments and, as a result, the enrolment procedure was faster. Therefore, reduction of thoracic segments in conocoryphids improved enrolment. Thus, if reduction of thoracic segments in a clade also occurred in derived taxa, the more plausible phylogenetic 
scenario may be the one shown in Figure 5D, with sphaeroidal enrolment-type as a derived trait. This strongly suggests that the ancestral ptychopariid trilobites, with higher numbers of segments, enrolled spirally, indicating that the reduction of thoracic segments was also a common trend over shorter timescales. Finally, the results emphasize that small morphological differences in phylogenetically close trilobites enable variation in enrolment type.

\section{Acknowledgements}

We thank Dan Sykes for assistance with X-ray microtomography. Trilobite photographs were taken by Isabel Pérez, University of Zaragoza. We thank Martina Korandová (Horák Museum, Rokycany, Czech Republic) for kind access to collections in her care. The authors wish to thank reviewers David Bruton and Shally Thomas for comments and suggestions that improved the manuscript. JE was funded by a Juan de la Cierva Grant (FPDI-2013-17337). SZ was funded by a Ramón y Cajal Grant (RYC-2012-10576) and project CGL2012-39471. JE and SZ are also supported by the project CGL2013-48877-P from the Spanish Ministry of Economy and Competitiveness. IR was funded by an 1851 Royal Commission Research Fellowship.

\section{References}

BERGERON, J. 1889. Étude géologique du massif ancien situé au sud du Plateau central. Annales des Sciences Géologiques, 22, 1-326.

ALVARO, J.J., ZAMORA, S., VIZCAINO, D. and AHLBERG, P. 2013. Guzhangian (mid Cambrian) trilobites from siliceous concretions of the Valtorres Formation, Iberian Chains, NE Spain. Geological Magazine, 150, 123-142.

ANGELIN, N.P. 1854. Palæontologia Scandinavica. I. Iconographia Crustacea Forma-tionis Transitionis, Fasc. II. Berlingska and Leipzig, Wiegel, Lund, 1-196.

BERGSTRÖM, J. 1973. Organisation, life, and systematics of trilobites. Fossils and Strata, 2 , $1-69$.

BRUTON, D.L. and HAAS, W. 1997. Functional morphology of Phacopinae (Trilobita) and the mechanics of enrolment. Palaeontographica Abteilung A, 245, 1-43.

COURTESSOLE, R. 1967. Une nouvelle espèce de Conocryphe «ocule» dans le Cambrien moyen du Nord-Leon. Bulletin de la Société Sciences Naturelle de Toulousse, 103, 491526. 
COTTON, T.J. 2001. The phylogeny and systematics of blind Cambrian ptychoparioid trilobites. Palaeontology, 44, 167-207.

ESTEVE, J. 2009. Enrolment in Conocoryphe heberti Munier-Chalmas \& Bergeron, 1889 (Middle Cambrian, Iberian Chain, NE Spain) and coaptative structures within family Conocoryphidae. Estudios Geologicos, 65, 167-182.

- 2013. Revision of the enrolment in Spanish Cambrian trilobites and its implications in trilobite evolution. Estudios Geologicos, 69, 209-225.

- HUGHES, N.C. and ZAMORA, S. 2011. Purujosa trilobite assemblage and the evolution of trilobite enrollment. Geology, 39, 575-578.

— ZAMORA, S., GOZALO, R. and LIÑAN, E. 2010. Sphaeroidal enrolment in middle Cambrian solenopleuropsine trilobites. Lethaia, 43, 478-493.

FATKA, O. and SZABAD, M. 2014. Cambrian biostratigraphy in the Pribram-Jince Basin (Barrandian area, Czech Republic). Bulletin of Geosciences, 89, 413-429.

HENRY, J.L. and CLARKSON, E. 1974. Enrollment and coap tations in some species of the Ordovician trilobite genus Placoparia. Fossils and Strata, 4, 87-95.

HUGHES, N.C. 2003. Trilobite tagmosis and body patterning from morphological and developmental perspectives. Integrative and Comparative Biology, 43, 185-206.

- CHAPMAN, R.E. and ADRAIN, J.M. 1999. The stability of thoracic segmentation in trilobites: a case study in developmental and ecological constraints. Evolution and Development, 1, 24-35.

LEROSEY-AUBRIL, R. and ANGIOLINI, L. 2009. Permian Trilobites from Antalya Province, Turkey, and Enrollment in Late Palaeozoic Trilobites. Turkish Journal of Earth Sciences, 18, 427-448.

ORTEGA-HERNÁNDEZ, J., ESTEVE, J. and BUTTERFIELD, N. J. 2013. Humble origins for a successful strategy: complete enrolment in early Cambrian olenellid trilobites. Biology Letters, 9.

ŠNAJDR, M. 1958. Trilobiti Ceského Stredního Kambria. Rozpravy ústredního ústavu geologického, 24, 1-280.

SUTTON, M. D., GARWOOD, R. J. and SIVETER, D. J. 2012. SPIERS and VAXML; A software toolkit for tomographic visualisation and a format for virtual specimen interchange. Palaeontologia Electronica, 15.

THORAL, M. 1946. Conocoryphidae Languedociens. Annales de l'Université de Lyon, série 3eme, section C, Sciences naturelles, 4, 1-74.

ZAMORA, S. 2010. Middle Cambrian echinoderms from north Spain show echinoderms diversified earlier in Gondwana. Geology, 38, 507-510.

- RAHMAN, I.A. and SMITH, A.B. 2013. The ontogeny of cinctans (stem-group Echinodermata) as revealed by a new genus, Graciacystis, from the middle Cambrian of 
Spain. Palaeontology, 56, 399-410.

\section{Figure Captions}

Fig. 1. Bailiaspis? glabrata (Angelin, 1854) from the Guzhangian siliceous concretions of the Valtorres Formation at Purujosa, A, CT-scan of two specimens (MPZ2017/310 and MPZ2017/311). B-C, CT-scan of MPZ 2017/310 used to create the 3D model, lateral (B) and frontal (C) views showing the pygidium tucked beneath the cephalon, D-F, MPZ 2017/310 Dorsal (D), frontal (E) and lateral (F) view of a latex cast. G-H, MPZ 2012/57, latex cast, lateral view $(G)$ showing the pleural pits fitting beneath the cephalon and anterior view $(H)$ showing the flexion of the last segments to put in contact the dorsal surface of the pygidium with the ventral side of the cephalon. Scale bar represents $5 \mathrm{~mm}(\mathrm{~A}-\mathrm{F})$ and $2 \mathrm{~mm}(\mathrm{G}-\mathrm{H})$.

Fig. 2. Parabailella languedocensis Thoral, 1946 from the hill slope of Vinice near Jince of the Barrandian area (C-12). A-B, Frontal view, A, Internal mould, B, virtual reconstruction. C-D Lateral view of the right side, internal mould (C), virtual reconstruction (D) and lateral view of the left side (E). Scale bar represents $5 \mathrm{~mm}$.

Fig. 3. A-C, Conocoryphe heberti (Munier-Chalmas \& Bergeron in Bergeron, 1889) from the Purujosa trilobite assemblage, Murero Formation, Cambrian Series 3, Drumian Stage. A, MPZ2017/319, latex cast of the dorsal view, B. MPZ2017/320, latex cast of the dorsal view. C, MPZ2017/320, latex cast of the ventral side of the cephalon, see the pygidium resting under the cephalon showing the typical sphaeroidal configuration. D-E, Parabailella languedocensis Thoral, 1946 from the Pardailhania hispida Zone, lowermost part of the Murero Formation, Cambrian Series 3, Drumian Stage, Purujosa. D. MPZ2017/314, latex cast in lateral view showing the flexion between the first segment and the cephalon. E. MPZ2017/315, latex cast in lateral view showing the flexion between the first segment and the cephalon. F, Occatharia sdzuyi (Courtessole, 1967), from the Solenopleuropsis thorali Zone, Oville Formation, 
Cambrian Series 3, Drumian Stage, Barrios de Luna, North Spain MPZ2009/15, internal mould in lateral view showing the flexion between the first segment and the cephalon. G-L. Bailiaspis? glabrata (Angelin, 1854) from the Guzhangian siliceous concretions of the Valtorres Formation at Purujosa. G-I, MPZ2017/312, internal mould of. G, dorsal view, H, posterior view, I, lateral view. J. MPZ2017/313, latex cast in lateral view showing the rear pleural tips (arrow). K. MPZ2012/60, internal mould in lateral view showing the anterior pleural tips (arrows). L. MPZ2012/36, latex cast in dorsal view showing the last two pleural tips of the thorax (arrow). Scale bar represents $5 \mathrm{~mm}(\mathrm{~A}-\mathrm{B}, \mathrm{F}-\mathrm{I})$ and $2 \mathrm{~mm}$ (C-E).

Fig. 4. Computer models of enrolment. A. Prone model in lateral view. B-C, Centre and axis of rotation of tergites. B, Model showing the position of the centre and axis of rotation in odd tergites (even tergites have been removed for a better visualization). C, Detail of the position of the centre and axis of rotation in an isolated tergite. D-F Spiral model. D-E, lateral views showing the relative position of the pygidium with respect of the cephalon in E, observe the pygidium is hidden beneath the cephalon. F, anterior view, observe the pygidium is almost not visible. G-I, Sphaeroidal model. G-H, lateral views showing the relative position of the pygidium with respect of the cephalon in $\mathrm{H}$, observe the pygidium is resting under the anterior arch of the cephalon. I, anterior view, observe the pygidium is visible. Not to scale

Fig. 5. A, Logarithm curve describing the enrolment mechanism of the 3D model created using Bailiaspis? grabata. B, Logarithm curves of spiral enrolment type with 15 segments (red), nonencapsulated sphaeroidal enrolment-type with 15 segments (green) and encapsulated sphaeroidal enrolment-type with 14 segments (purple). C, Angle ratio between adjacent segments. D-E, Phylogenetic hypothesis of the conocoryphid clade, rooted using Elrathia kingie (D) and using Ptychoparia striata (E), (after Cotton 2001). 


\section{Supplementary Information}

All supplementary information can be downloaded here

https://drive.google.com/open?id=0B4giy8jCjrmXVGlfMkFIMDdCUUU

Data 1. Slices from XMT scan of two enrolled specimens of Bailiaspis? glabrata (MPZ2017/310-311).

Data 2. Slices from XMT scan of one enrolled specimen of Parabailella languedocensis (C-12).

Model 1. Interactive 3-D reconstruction of Bailiaspis? glabrata (MPZ2017/310) in VAXML format.

Model 2. Interactive 3-D reconstruction of Bailiaspis? glabrata (MPZ2017/311) in VAXML format.

Model 3. Interactive 3-D reconstruction of Parabailella languedocensis (C-12) in VAXML format.

Movie 1. Movie showing in real-time the logarithm curve of the spiral and sphaeroidal enrolment mechanism of the 3D model created using Bailiaspis? grabata. Movie 2. 3-D model of Bailiaspis? glabrata showing the enrolment procedure. 




Fig. 1. Bailiaspis? glabrata (Angelin, 1854) from the Guzhangian siliceous concretions of the Valtorres Formation at Purujosa, A, CT-scan of two specimens (MPZ2017/310 and MPZ2017/311). B-C, CT-scan of MPZ 2017/310 used to create the 3D model, lateral (B) and frontal (C) views showing the pygidium tucked beneath the cephalon, D-F, MPZ 2017/310 Dorsal (D), frontal (E) and lateral (F) view of a latex cast. G-H, MPZ 2012/57, latex cast, lateral view (G) showing the pleural pits fitting beneath the cephalon and anterior view $(H)$ showing the flexion of the last segments to put in contact the dorsal surface of the pygidium with the ventral side of the cephalon. Scale bar represents $5 \mathrm{~mm}(A-F)$ and $2 \mathrm{~mm}(\mathrm{G}-\mathrm{H})$.

\section{$256 \times 397 \mathrm{~mm}(300 \times 300 \mathrm{DPI})$}




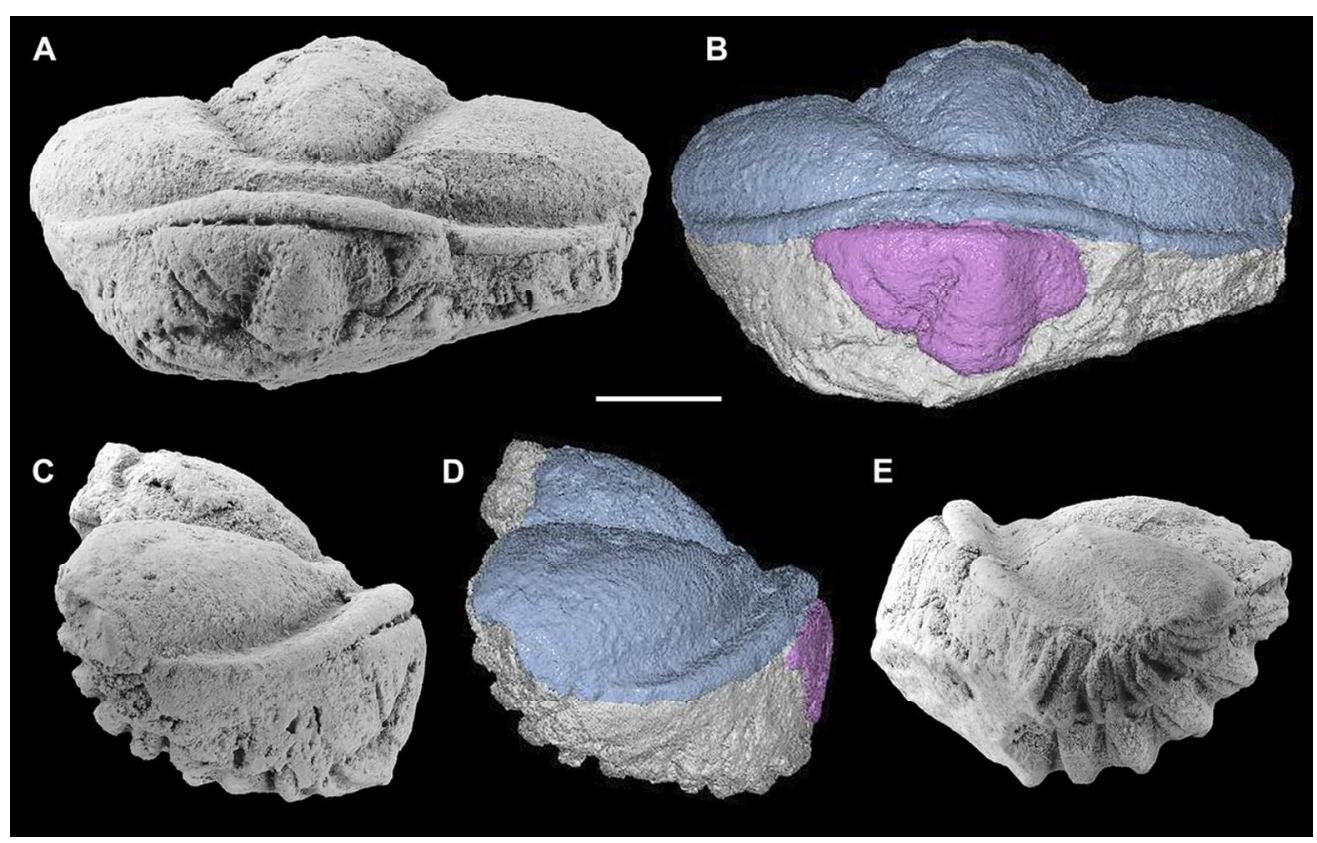

Fig. 2. Parabailella languedocensis Thoral, 1946 from the hill slope of Vinice near Jince of the Barrandian area (C-12). A-B, Frontal view, A, Internal mould, B, virtual reconstruction. C-D Lateral view of the right side, internal mould (C), virtual reconstruction (D) and lateral view of the left side (E). Scale bar represents $5 \mathrm{~mm}$.

$104 \times 66 \mathrm{~mm}(300 \times 300$ DPI $)$ 

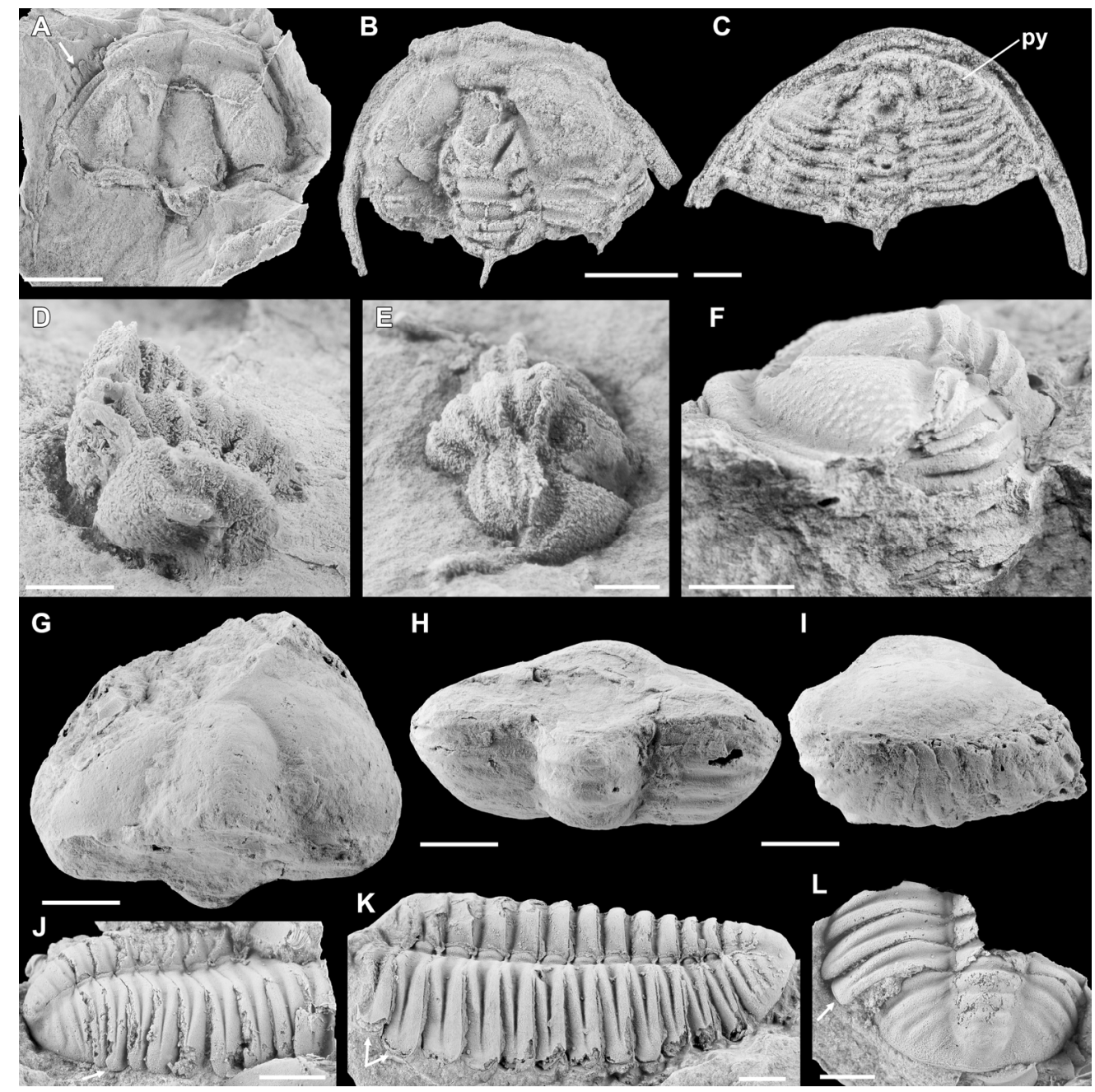

Fig. 3. A-C, Conocoryphe heberti (Munier-Chalmas \& Bergeron in Bergeron, 1889) from the Purujosa trilobite assemblage, Murero Formation, Cambrian Series 3, Drumian Stage. A, MPZ2017/319, latex cast of the dorsal view, B. MPZ2017/320, latex cast of the dorsal view. C, MPZ2017/320, latex cast of the ventral side of the cephalon, see the pygidium resting under the cephalon showing the typical sphaeroidal configuration. D-E, Parabailella languedocensis Thoral, 1946 from the Pardailhania hispida Zone, lowermost part of the Murero Formation, Cambrian Series 3, Drumian Stage, Purujosa. D. MPZ2017/314, latex cast in lateral view showing the flexion between the first segment and the cephalon. E. MPZ2017/315, latex cast in lateral view showing the flexion between the first segment and the cephalon. F, Occatharia sdzuyi (Courtessole, 1967), from the Solenopleuropsis thorali Zone, Oville Formation, Cambrian Series 3, Drumian Stage, Barrios de Luna, North Spain MPZ2009/15, internal mould in lateral view showing the flexion between the first segment and the cephalon. G-L. Bailiaspis? glabrata (Angelin, 1854) from the Guzhangian siliceous concretions of the Valtorres Formation at Purujosa. G-I, MPZ2017/312, internal mould of. G, dorsal view, H, posterior view, I, lateral view. J. MPZ2017/313, latex cast in lateral view showing the rear pleural tips (arrow). K. MPZ2012/60, internal mould in lateral view showing the anterior pleural tips (arrows). L. MPZ2012/36, latex cast in dorsal view showing the last two pleural tips of the thorax (arrow). Scale bar represents $5 \mathrm{~mm}$ (A-B, $\mathrm{F}-\mathrm{I})$ and $2 \mathrm{~mm}(\mathrm{C}-\mathrm{E})$. 
Fig. 4. Computer models of enrolment. A. Prone model in lateral view. B-C, Centre and axis of rotation of tergites. $B$, Model showing the position of the centre and axis of rotation in odd tergites (even tergites have been removed for a better visualization). C, Detail of the position of the centre and axis of rotation in an isolated tergite. D-F Spiral model. D-E, lateral views showing the relative position of the pygidium with respect of the cephalon in $\mathrm{E}$, observe the pygidium is hidden beneath the cephalon. $\mathrm{F}$, anterior view, observe the pygidium is almost not visible. G-I, Sphaeroidal model. G-H, lateral views showing the relative position of the pygidium with respect of the cephalon in $\mathrm{H}$, observe the pygidium is resting under the anterior arch of the cephalon. I, anterior view, observe the pygidium is visible. Not to scale.

\section{$212 \times 270 \mathrm{~mm}(300 \times 300$ DPI)}





D

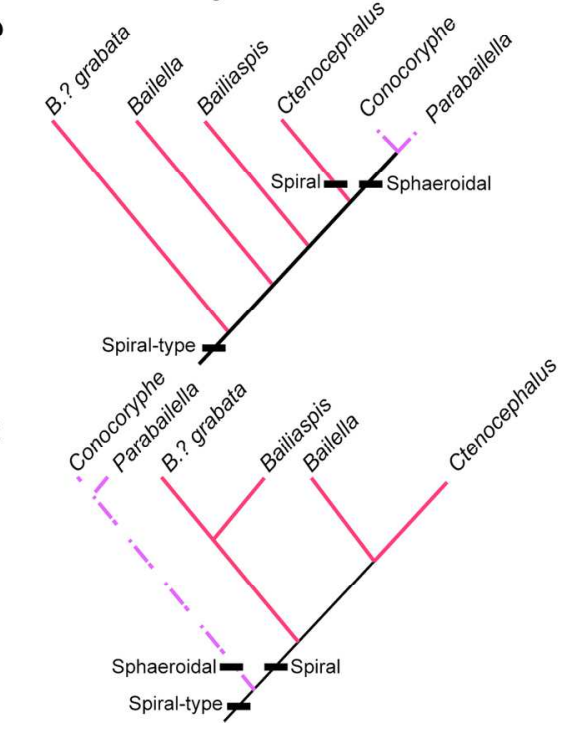

Fig. 5. A, Logarithm curve describing the enrolment mechanism of the 3D model created using Bailiaspis? grabata. B, Logarithm curves of spiral enrolment type with 15 segments (red), non-encapsulated sphaeroidal enrolment-type with 15 segments (green) and encapsulated sphaeroidal enrolment-type with 14 segments (purple). C, Angle ratio between adjacent segments. D-E, Phylogenetic hypothesis of the conocoryphid clade, rooted using Elrathia kingie (D) and using Ptychoparia striata (E), (after Cotton 2001).

$$
156 \times 148 \mathrm{~mm}(300 \times 300 \text { DPI })
$$

